\title{
Physician Assistants in Primary Care: Trends and Characteristics
}

Bettie Coplan, MPAS, PA-C

James Cawley, MPH, PA-C ${ }^{2}$

James Stoebr, $P b D^{1}$

'Physician Assistant Program, College of Health Sciences, Midwestern University, Glendale Campus, Glendale, Arizona

${ }^{2}$ School of Public Health and Health Services and School of Medicine and Health Sciences, George Washington University, Washington, DC
Conflicts of interest: authors report none.

\section{CORRESPONDING AUTHOR}

Bettie Coplan, MPAS, PA-C Physician Assistant Program Northern Arizona University $425 \mathrm{~N} 5$ th St

Phoenix, AZ 85004

bettie.coplan@nau.edu

\begin{abstract}
PURPOSE Physician assistants (PAs) have made major contributions to the primary care workforce. Since the mid-1990s, however, the percentage of PAs working in primary care has declined. The purpose of this study was to identify demographic characteristics associated with PAs who practice in primary care.

METHODS We obtained data from the 2009 American Academy of Physician Assistants' Annual Census Survey and used univariate analyses, logistic regression analyses, and $\chi^{2}$ trend tests to assess differences in demographics (eg, age, sex, race) between primary care and non-primary care PAs. Survey respondents had graduated from PA school between 1965 and 2008.
\end{abstract}

RESULTS Of 72,433 PAs surveyed, 19,608 participated (27\% of all PAs eligible to practice). Incomplete questionnaires were eliminated resulting in a final sample of 18,048 . One-third of PAs reported working in primary care. Female, Hispanic, and older PAs were more likely to work in primary care practice. Trend tests showed a decline in the percentage of PAs working in primary care in the sample overall (average $0.3 \%$ decrease per year; $P<.0001$ ). In the cohort of 2004-2008 graduates, however, the percentage of primary care PAs increased slightly by an average of $0.9 \%$ per year $(P=.02)$. Nonetheless, the low response rate of the census limits the ability to generalize these findings to the total population of PAs.

CONCLUSIONS Demographics associated with an increased likelihood of primary care practice among PAs appear to be similar to those of medical students who choose primary care. Knowledge of these characteristics may help efforts to increase the number of primary care PAs.

Ann Fam Med 2013;11:75-79. doi:10.1370/afm.1432.

\section{INTRODUCTION}

I $\mathrm{n}$ the mid-1960s, the need for greater patient access to primary care was a principal motivator for establishing the physician assistant (PA) profession ${ }^{1}$ and, until the mid-1990s, most PAs practiced in primary care settings. ${ }^{2,3}$ Although the absolute number of PAs working in primary care has increased overall, the percentage of PAs in primary care has declined from $50.8 \%$ in 1996 to $31 \%$ in $2010 .{ }^{4}$ This trend correlates with a similar trend among physicians. ${ }^{3,5}$

The diminishing fraction of new clinicians entering primary care has become a major concern across professions. In 2010, the American College of Physicians (ACP) and the American Academy of Physician Assistants (AAPA) made a joint commitment to reverse the declines in primary care practice. ${ }^{3}$ The PA profession may therefore want to identify characteristics of those most likely to practice in primary care settings. ${ }^{6}$ Medical student demographic factors associated with primary care practice include female sex, rural background, and older age. ${ }^{7}$ We wondered if these correlations hold true for PAs. Hence, the goals of this study were to assess demographic characteristics associated with PA practice in primary care and to ascertain related trends over time. 


\section{METHODS}

\section{Sample and Instrument}

We analyzed data from the 2009 AAPA's Annual

Census Survey. The AAPA distributes the survey questionnaire to all PAs eligible to practice and includes respondents who graduated from PA school between 1965 and 2008. The census consists of 30 questions related to PA workforce issues and serves as a primary resource for data on the PA profession (http://www. aapa.org/research/data_and_statistics/resources/item. aspx? $\mathrm{id}=2502){ }^{8}$

\section{Analysis}

We used univariate analyses and logistic regression analyses to determine the relationship between practice groups (primary care vs non-primary care PAs) and each demographic characteristic (age, sex, race, etc). Primary care was defined as family medicine, general pediatrics, and general internal medicine. Results are reported in the form of odds ratios and average differences with 95\% confidence intervals Chi-squared trend tests were used to determine if the proportion of PAs in primary care varied across age, year of PA school graduation, and age at time of graduation. To examine trends among recent graduates, we analyzed a subsample that included only PAs who graduated from PA programs between 2004 and 2008.

\section{RESULTS}

Of the 72,433 PAs surveyed, 19,608 responded (response rate of $27 \%$ ). We eliminated from analysis 1,560 respondents returning incomplete questionnaires, which resulted in a final sample of 18,048 . Respondents in the final sample averaged 40.9 years of age and 30.3 years of age at the time of graduation; $64.7 \%$ were female and $88.4 \%$ were white (Table 1 ).

In all, $33.4 \%(95 \% \mathrm{CI}, 32.7 \%-34.1 \%)$ of the PAs, or 6,033 , reported working in primary care. Group analyses revealed an association between primary care practice and sex, age at time of questionnaire completion, age at time of graduation, and race (all comparisons, $P<.001$ ) (Table 1). Analysis of associations with race/ ethnicity found that Hispanics were significantly more likely to practice in primary care compared with whites $(P<.001)$. Point estimates and 95\% confidence intervals for the proportions in primary care are illustrated in a forest plot (Figure 1).

Trend tests indicated a significant decrease in the proportion of PAs in primary care each year but revealed a significant increase in the proportion of primary care PAs associated with older age at time of graduation (average $0.5 \%$ increase per year $P<.0001$ ) and age older than 40 years at the time of questionnaire completion (average $0.4 \%$ increase per year ${ }_{i} P<.0001$ )

(Table 2, Figure 2). Trend analyses over the latest 5

\section{Table 1. Demographic Characteristics of Primary Care vs Non-Primary Care Physician Assistants}

\begin{tabular}{|c|c|c|c|c|c|c|}
\hline Characteristic & $\begin{array}{c}\text { All, } \% \\
(\mathrm{~N}=18,048)\end{array}$ & $\begin{array}{c}\text { Non-Primary } \\
\text { Care, No. } \\
\text { (n=12,015) }\end{array}$ & $\begin{array}{c}\text { Primary } \\
\text { Care, No. } \\
(n=6,033)\end{array}$ & $\begin{array}{c}\text { Primary Care, } \\
\%(95 \% \mathrm{CI})\end{array}$ & $\begin{array}{l}\text { Odds Ratio } \\
(95 \% \mathrm{Cl})\end{array}$ & $P$ Value $^{a}$ \\
\hline \multicolumn{7}{|l|}{ Sex } \\
\hline Female & 64.7 & 7,337 & 3,909 & $34.8(33.9-35.6)$ & $1.21(1.13-1.30)$ & $<.001$ \\
\hline Male & 35.3 & 4,271 & 1,876 & $30.5(29.3-31.7)$ & Ref & \\
\hline Race, categorical & & & & & & $<.001$ \\
\hline Asian/Pacific Islander & 4.0 & 466 & 186 & $28.5(25.1-32.2)$ & $0.81(0.68-0.96)$ & .02 \\
\hline Black & 2.8 & 299 & 162 & $35.1(30.8-39.7)$ & $1.10(0.90-1.33)$ & .34 \\
\hline Hispanic & 3.7 & 335 & 262 & $43.9(39.9-48.0)$ & $1.59(1.34-1.87)$ & $<.001$ \\
\hline American Indian & $<1$ & 59 & 41 & $41.0(31.3-51.3)$ & $1.41(0.94-2.09)$ & .09 \\
\hline Other & $<1$ & 59 & 16 & $21.3(12.7-32.3)$ & $0.55(0.31-0.93)$ & .03 \\
\hline \multicolumn{7}{|l|}{ Race, dichotomous } \\
\hline White & 88.4 & 9,582 & 4,726 & $33.0(32.3-33.8)$ & Ref & \\
\hline \multirow[t]{2}{*}{ Nonwhite $^{b}$} & 11.6 & 1,218 & 667 & $35.4(33.2-37.6)$ & $1.11(1.00-1.23)$ & .04 \\
\hline & & \multicolumn{2}{|c|}{ Mean } & & $\begin{array}{c}\text { Mean Difference } \\
(95 \% \mathrm{CI})\end{array}$ & \\
\hline Age, y & - & 40.2 & 42.4 & - & $2.2(1.9-2.6)$ & $<.001^{c}$ \\
\hline Age at graduation, y & - & 30.0 & 31.0 & - & $1.0(0.8-1.2)$ & $<.001^{c}$ \\
\hline \multicolumn{7}{|c|}{ Ref $=$ reference category for odds ratios. } \\
\hline \multicolumn{7}{|c|}{$\begin{array}{l}\text { Notes: All percentages were calculated from nonmissing data. A total of } 1,560 \\
\text { a Unless otherwise noted, the Fisher exact test was used to calculate } P \text { values. } \\
\text { b Sum of categories other than white. } \\
\text { " Two-sample } t \text { test. }\end{array}$} \\
\hline
\end{tabular}


graduating classes (2004-2008) indicated a significant increase in the proportion of primary care PAs over this time period (average $0.9 \%$ increase per year $r_{i} P=.02$ ) including an increase in women practicing in primary care (average $1.1 \%$ increase per year ${ }_{i} P=.02$ ) (Table 2 ).

\section{DISCUSSION}

Overall, we found that PAs working in primary care have demographic characteristics similar to those of medical students who choose general primary care specialties. A 2010 systematic review determined that 6 factors are associated with a medical student's commitment to primary care practice: female sex, older age, Latino ethnicity, lower socioeconomic status, receipt of

\section{Figure 1. Percentage of physician assistants practicing in primary care by demographic characteristics: point estimates and $95 \%$ confidence intervals.}

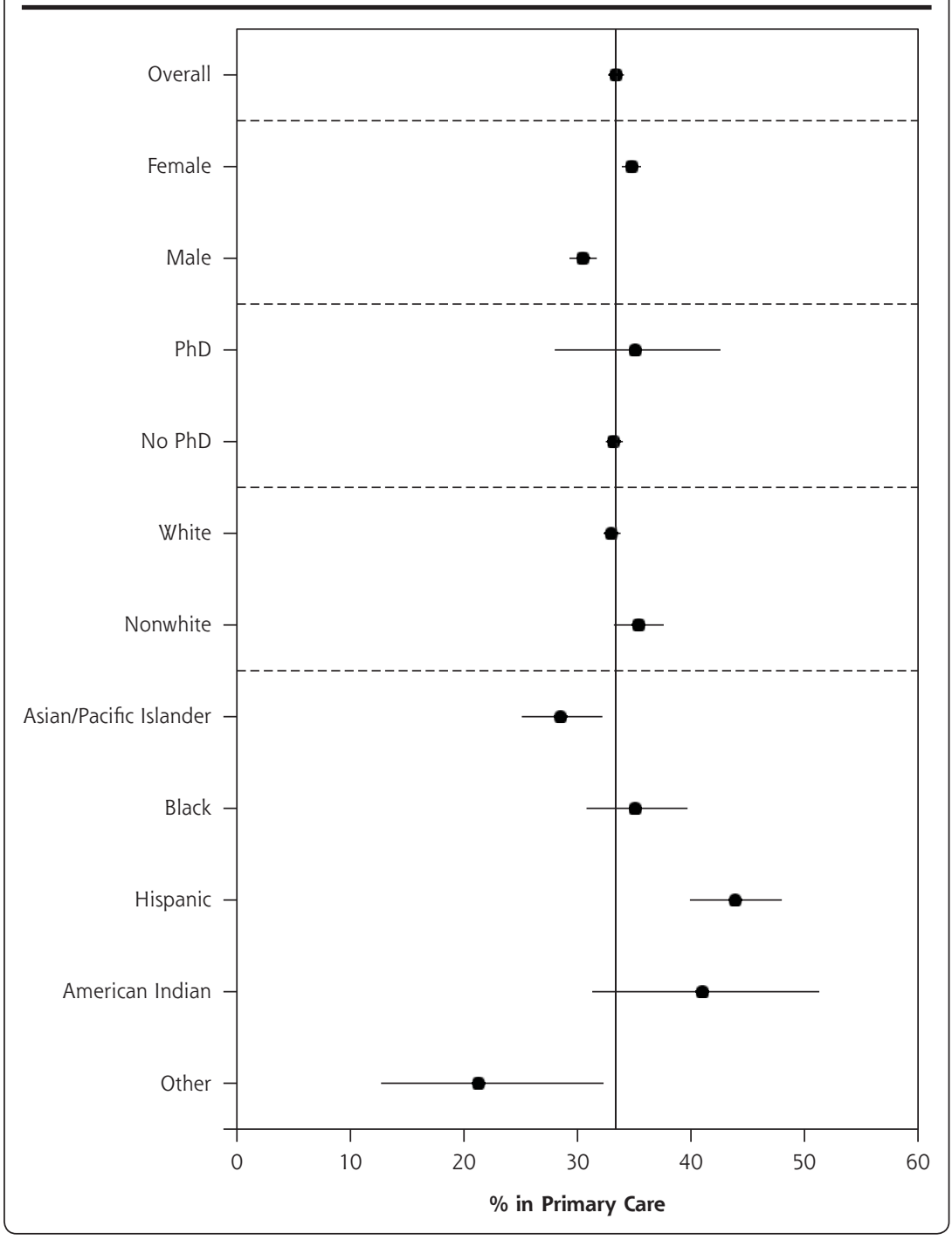

a National Health Service Corps scholarship, and intention to practice in primary care at the time of medical school matriculation. ${ }^{7}$ We found that PA practice in primary care is also more likely among those who are female, older, and Hispanic. The only other recent study of the relationship between demographics and PA practice setting also found that minority and older PAs are more likely to work in primary care. ${ }^{8}$ Furthermore, similar to the findings for medical students, the data on PAs identified a positive association between primary care practice and lower economic status. ${ }^{6}$

A US study of specialty choices among PAs between 1997 and 2006 found that the growth rate of PA practice in primary care was lower than the overall growth of the profession. ${ }^{5}$ Similarly, we found an overall decline in the percentage of PAs in primary care each year. In the cohort of 2004-2008 graduates, however, the percentage of primary care PAs increased modestly, by an average of $0.9 \%$ each year. It should be noted that nearly one-half of all PAs change specialties at some time during their careers. ${ }^{9}$ Interestingly, primary care specialties in general have the most staying power, with $53 \%$ of those in family practice making no change. ${ }^{9}$ We cannot predict the practice patterns of new graduates, but historically, the net decrease in the number of PAs in family medicine correlates with smaller percentages of new graduates choosing family practice. ${ }^{9}$ The slight upward trend of new graduate selection of primary care may therefore reflect some stabilization in the percentage of primary care PAs.

In general, medical schools and PA programs have had little success recruiting matriculants into primary care. ${ }^{7,10}$ Educational programs may therefore want to consider factors associated with an increased likelihood of primary care practice when recruiting and selecting applicants. In addition, further research could be aimed at identifying the particular factors that cause practicing PAs to transition into and out of primary care. 
Table 2. Trends in Primary Care Practice Among Physician Assistants by Demographic Characteristics

\begin{tabular}{|c|c|c|c|c|}
\hline \multirow[b]{2}{*}{ Characteristic } & \multicolumn{2}{|c|}{ All Graduates } & \multicolumn{2}{|c|}{ 2004-2008 Graduates } \\
\hline & $P$ Value & $\begin{array}{c}\text { Estimated } \\
\text { Mean Change } \\
\text { per Year, \% }\end{array}$ & $P$ Value & $\begin{array}{c}\text { Estimated } \\
\text { Mean Change } \\
\text { per Year, \% }\end{array}$ \\
\hline $\begin{array}{l}\text { Overall by graduation } \\
\text { year }\end{array}$ & $<.0001$ & -0.3 & .02 & 0.9 \\
\hline \multicolumn{5}{|l|}{ Sex by graduation year } \\
\hline Male & $<.0001$ & -0.4 & .72 & 0.3 \\
\hline Female & $<.0001$ & -0.3 & .02 & 1.1 \\
\hline \multicolumn{5}{|l|}{$\begin{array}{l}\text { Race, dichotomous, by } \\
\text { graduation year }\end{array}$} \\
\hline White & $<.0001$ & -0.3 & .08 & 0.8 \\
\hline Nonwhite & .06 & -0.2 & .06 & 2.2 \\
\hline \multicolumn{5}{|l|}{$\begin{array}{l}\text { Race, categorical, by } \\
\text { graduation year }\end{array}$} \\
\hline Asian/Pacific Islander & .50 & -0.1 & .003 & 5.3 \\
\hline Black & .40 & -0.4 & .88 & -0.4 \\
\hline Hispanic & .61 & -0.1 & .66 & -0.9 \\
\hline American Indian & .44 & -0.2 & .71 & 0.4 \\
\hline Other & .36 & -5.8 & .52 & -0.5 \\
\hline $\begin{array}{l}\text { Overall by age at ques- } \\
\text { tionnaire completion }\end{array}$ & $<.0001$ & 0.4 & .01 & 0.2 \\
\hline$\leq 40$ y & .67 & -0.1 & .92 & 0.0 \\
\hline$>40 y$ & $<.0001$ & 0.5 & .20 & 0.4 \\
\hline $\begin{array}{l}\text { Overall by age at } \\
\text { graduation }(\geq 20 y)\end{array}$ & $<.0001$ & 0.5 & .004 & 0.3 \\
\hline
\end{tabular}

Figure 2. Trend in the percentage of primary care PAs by year of graduation from 1975 to 2008 .

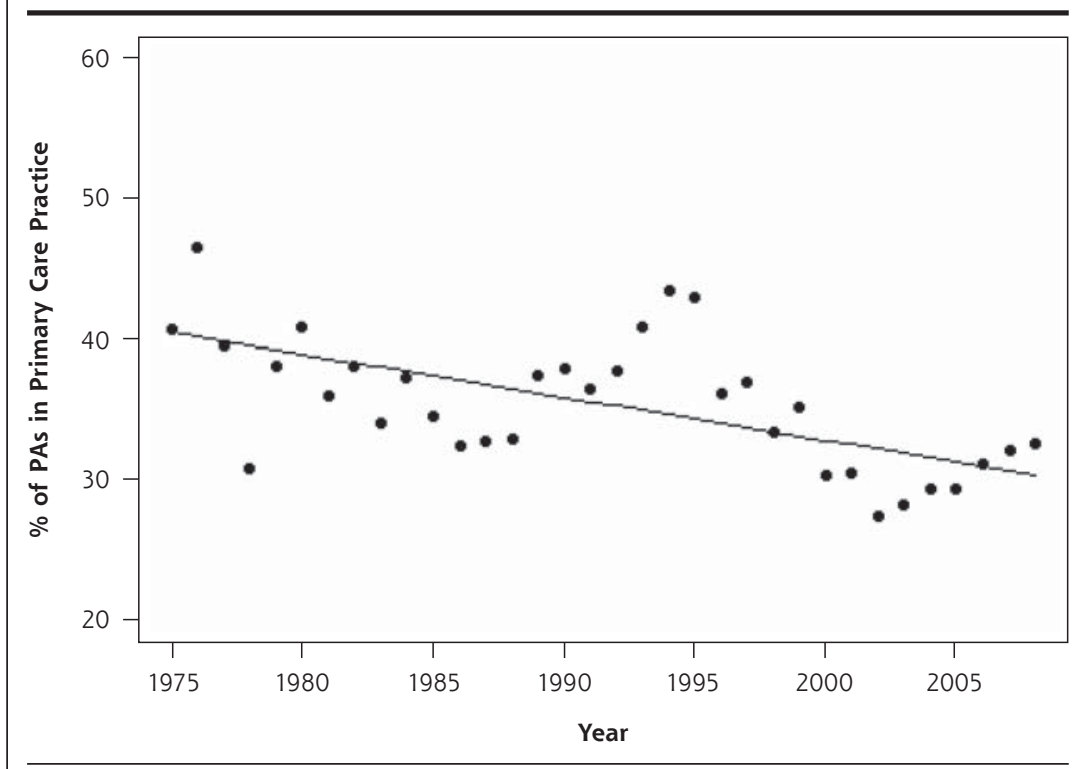

$\mathrm{PA}=$ physician assistant.

Note: Trend analysis (regression) included data for all responding graduates. Plot was started at graduation year of 1975 because of limited data from PAs graduating between 1965 and 1974.
The AAPA Census Survey targets all practicing PAs, and the proportion of respondents by sex was nearly identical to the current sex distribution of certified PAs. ${ }^{11}$ The survey's $27 \%$ response rate, however, raises the risk of self-selection, self-report, and nonresponse bias. For example, those in the profession longer are less likely to respond. ${ }^{12}$ This group represents a smaller proportion of the profession but also includes PAs who graduated from PA school at a time when more graduates entered primary care. We were therefore limited in our ability to generalize the results to the entire population of PAs. Finally, the survey was crosssectional and not prospective, and was not designed for analysis of demographic characteristics associated with specialties. Despite these limitations, our findings support prior research that indicates that women, older clinicians, and Hispanics are more likely to practice in primary care. ${ }^{6,7,13}$

PA practice trends mirror the practice trends of physicians. Consequently, actions that increase the number of primary care physicians are also likely to increase the percentage of primary care PAs. The PA profession should therefore continue to support workforce policy measures that successfully increase the number of primary care clinicians including loan repayment, improved levels of reimbursement for primary care physicians, and expansion of Title VII, Section 747 of the Public Health Service Act, which aims to increase the quality, size, and diversity of the primary care workforce. ${ }^{14}$

To read or post commentaries in response to this article, see it online at http://www.annfammed.orgl content/11/1/75.

Key words: physician assistants; workforce; primary health care 
Submitted November 23, 2011; submitted, revised, June 8, 2012; accepted June 19, 2012.

Acknowledgments: The authors wish to thank the American Academy of Physician Assistants for providing the data for analysis and to acknowledge Kent Armeson for statistical support.

\section{References}

1. Jones PE, Cawley JF. Physician assistants and health system reform. Clinical capabilities, practice activities, and potential roles. JAMA. 1994;271(16):1266-1272.

2. American College of Physicians. Physician assistants and nurse practitioners. Ann Intern Med. 1994;121(9):714-716.

3. American College of Physicians. Internists and Physician Assistants: Team-Based Primary Care, policy monograph. 2010. http://www. acponline.org/advocacy/where_we_stand/policy/internists_asst.pdf. Accessed Aug 12, 2011.

4. American Academy of Physician Assistants. Physician Assistant Census Report: Results from the 2010 AAPA Census. http://www.aapa.org/ uploadedFiles/2010\%20Census\%20Report\%20National\%20_Final. pdf. Accessed Sep 29, 2011.

5. Morgan PA, Hooker RS. Choice of specialties among physician assistants in the United States. Health Aff (Millwood). 2010;29(5):887-892.

6. Muma RD, Kelley J, Lies S. Relationships of demographic background and practice setting among practicing physician assistants in the United States. J Physician Assist Educ. 2010;21(2):15-21.
7. Bennett KL, Phillips JP. Finding, recruiting, and sustaining the future primary care physician workforce: a new theoretical model of specialty choice process. Acad Med. 2010;85(10 Suppl):S81-S88.

8. American Academy of Physician Assistants. 2009 AAPA Physician Assistant Census National Report. http://www.aapa.org/research/data_ and_statistics/resources/item.aspx?id=600. Accessed June 4, 2012.

9. Hooker RS, Cawley JF, Leinweber W. Career flexibility of physician assistants and the potential for more primary care. Health Aff (Millwood). 2010;29(5):880-886.

10. Sandy LG, Bodenheimer T, Pawlson LG, Starfield B. The political economy of U.S. primary care. Health Aff (Millwood). 2009;28(4): 1136-1145.

11. Danielsen RD, Lathrop J, Arbet S. The certified physician assistant in the United States: a 2011 snapshot. JAAPA. 2012;25(4):58.

12. American Academy of Physician Assistants. Trends in the Physician Assistant Profession 1991-2003. http://www.aapa.org/uploadedFiles/ content/Common/Files/91-03trends-report.pdf. Accessed June 4, 2012.

13. Hooker RS, Ramos C, Daly RP, Fang R. The characteristics of clinically active older physician assistants. JAAPA. 2012;25(1):48, 50, 52-53.

14. Robert Graham Center. Title VII's decline: Shrinking investment in the primary care training pipeline. 2009. http://www.graham-center. org/online/graham/home/publications/onepagers/2009/op61-title-vii. html. Accessed Dec 6, 2012 